\title{
Traumatic rupture of thoracic epidural capillary hemangioma resulting in acute neurologic deficit: illustrative case
}

\author{
Reilly L. Kidwell, BS, ${ }^{1}$ Lauren E. Stone, MD, ${ }^{1}$ Vanessa Goodwill, MD, ${ }^{2}$ and Joseph D. Ciacci, MD ${ }^{1}$ \\ Departments of ${ }^{1}$ Neurosurgery and ${ }^{2}$ Neuropathology, University of California, San Diego, La Jolla, California
}

BACKGROUND Thoracic epidural capillary hemangioma is exceedingly rare, with only a few reported cases. The typical presentation usually includes chronic, progressive symptoms of spinal cord compression in middle-aged adults. To the authors' knowledge, this case is the first report in the literature of acute traumatic capillary hemangioma rupture.

OBSERVATIONS A 22-year-old male presented with worsening lower extremity weakness and paresthesias after a fall onto his spine. Imaging showed no evidence of spinal fracture but revealed an expanding hematoma over 24 hours. Removal of the lesion demonstrated a ruptured capillary hemangioma.

LESSONS This unique case highlights a rare occurrence of traumatic rupture of a previously unknown asymptomatic thoracic capillary hemangioma in a young adult.

https://thejns.org/doi/abs/10.3171/CASE21309

KEYWORDS thoracic spine; trauma; hemangioma; laminectomy

Capillary hemangiomas are benign clusters of abnormal blood vessels that are most often found in the skin or soft tissues, commonly in pediatric patients. ${ }^{1}$ They have a distinct lobulated structure, consisting of vascular collections fed by a single artery, which differentiates them from malignant vascular proliferations, including hemangioblastomas, hemangioendotheliomas, and hemangiopericytomas. ${ }^{2}$ Though hemangiomas frequently originate from the vertebral body, they rarely involve the spinal cord and, if present, most commonly occupy the intradural/ extramedullary space. ${ }^{3}$ Epidural capillary hemangiomas are exceedingly rare and typically present with chronic progressive symptoms of spinal cord compression. ${ }^{4}$ Here we present a unique case of traumatic thoracic epidural capillary hemangioma rupture causing acute lower extremity weakness and paresthesias and requiring urgent spinal cord decompression and hematoma evacuation.

\section{Illustrative Case}

A 22-year-old male without significant medical history presented with acute-onset bilateral lower extremity weakness and sensory loss after falling $10 \mathrm{ft}$. onto his back during a military training exercise. On initial presentation to the trauma bay, the patient was unable to move his feet or toes and reported complete loss of sensation at and below the midcalf. He was able to lift his leg only with assistance, and his Babinski sign was negative. The finding of a noncontrast computed tomographic scan of the cervical, thoracic, and lumbar spine was negative for acute fracture or notable trauma (Fig. 1). On neurosurgical clinical examination, the patient's strength was $5 / 5$ in the proximal lower extremities bilaterally and had improved from his initial presentation to $3 / 5$ in his bilateral distal lower extremities, though still with absent sensation in both feet up to the ankle. Strength and sensation were preserved in the upper extremities. Subsequent magnetic resonance imaging (MRI) of the thoracic spine demonstrated a T2-hyperintense, T1-hypointense dorsal epidural lesion at the level of T10-11, measuring 6-7 $\mathrm{mm}$ in the anteroposterior (AP) dimension, mildly compressing the spinal cord (Fig. 2). MRI was ordered; however, given his clinical improvement, the patient was assessed to be clinically stable at this time, without need for emergent surgery.

The day after admission, the patient developed progressive left lower extremity weakness with $2 / 5$ strength in the distal left leg. Repeat

ABBREVIATIONS AP = anteroposterior; $M R I=$ magnetic resonance imaging. INCLUDE WHEN CITING Published November 22, 2021; DOI: 10.3171/CASE21309. SUBMITTED May 18, 2021. ACCEPTED August 04, 2021.

(c) 2021 The authors, CC BY-NC-ND 4.0 (http://creativecommons.org/licenses/by-nc-nd/4.0/). 

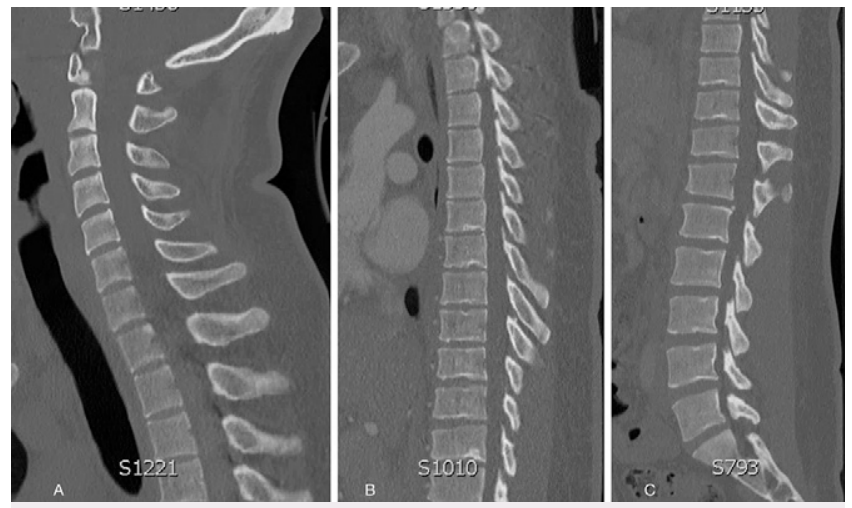

FIG. 1. Computed tomography of (A) cervical, (B) thoracic, and (C) lumbar spine without evidence of acute traumatic injury.

MRI demonstrated interval enlargement of the epidural lesion to 7-8 $\mathrm{mm}$ $A P$, with increased spinal cord compression and progressive delayed enhancement postcontrast (Figs. 3 and 4). The patient consented to emergency thoracic decompression and was taken to the operating room within 3 hours for T10-11 laminectomies and removal of the epidural mass and surrounding hematoma. Intraoperatively, removal of the bone at T11 revealed a hemorrhagic, well-circumscribed, compressive epidural mass lesion consistent with a possible hematoma versus a more organized mass. A specimen sent for pathology demonstrated a well-circumscribed proliferation of endothelial cells forming vascular cavities, surrounded by a rind of fibrous connective tissue, consistent with capillary hemangioma (Fig. 5).

Postoperatively, the patient's left lower extremity weakness was initially unchanged but showed moderate improvement over the course of several days to $3 / 5$ strength in the distal lower leg at best. His sensation improved to $50 \%$ at the left foot, with some persistent allodynia and hyperesthesia in the left leg and calf. The thoracic dermatomes remained intact. The patient was ultimately discharged to the naval
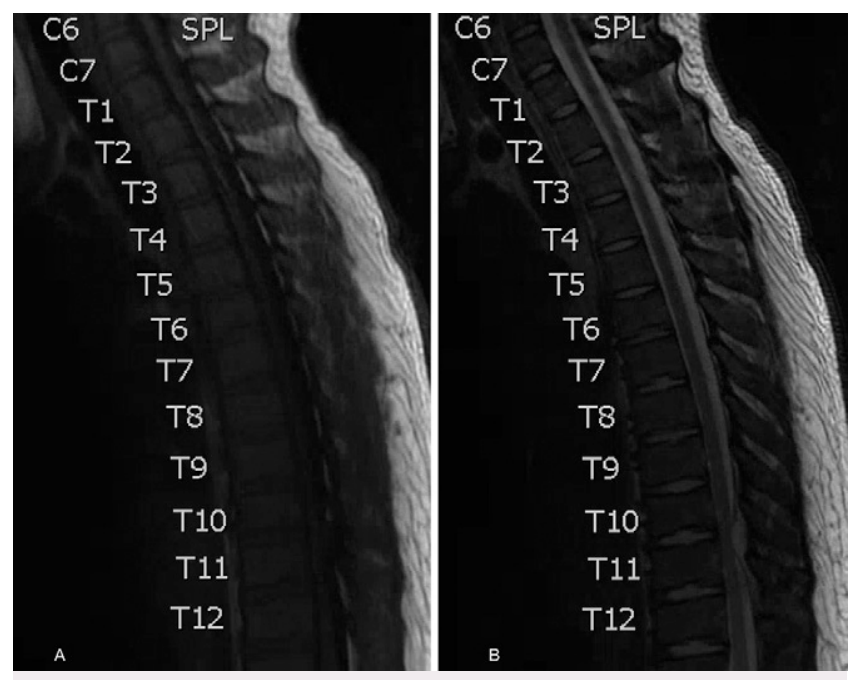

FIG. 2. MRI upon presentation showing a 6-7-mm dorsal epidural lesion at the level of T10-11 demonstrating (A) T1 hypointensity and (B) T2 hyperintensity with mild compression of the spinal cord.
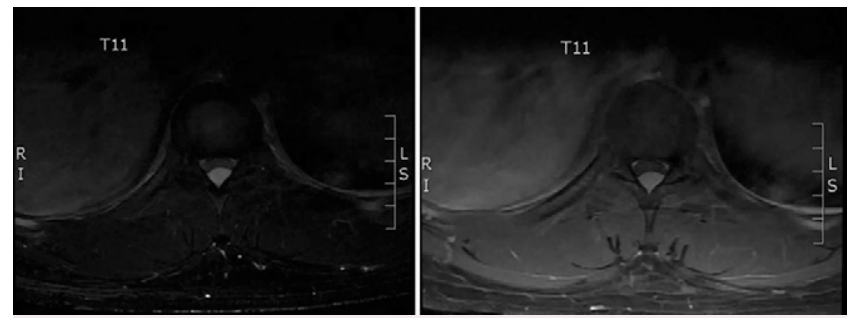

FIG. 3. Axial MRI of the T spine at T11. A: With contrast. B: Without contrast.

hospital, where he returned to complete motor and sensory function after several months of intensive rehabilitation.

\section{Discussion}

\section{Observations}

Capillary hemangiomas are benign clusters of abnormal blood vessels that are most often seen in the skin or soft tissues, commonly in pediatric patients. ${ }^{3}$ They are distinguished from cavernous angiomas and malignant vascular tumors of the central nervous system by their lobulated architecture, composed of tangles of capillaries separated by fibrous tissue. ${ }^{2}$ They also commonly stain positive for CD31, an endothelial cell marker. ${ }^{1}$ Grossly, capillary hemangiomas appear as a reddish purple mass with a rich vascular network and must be carefully dissected from feeding vessels to maintain hemostasis. Radiologically, these present as a well-defined mass with $\mathrm{T} 1$ signal isointense to the spinal cord and hyperintensity on T2. ${ }^{5}$ They are often confused preoperatively with meningiomas or large nerve sheath tumors.

To our knowledge, this case is the first report of a traumatic thoracic epidural capillary hemangioma rupture. Thoracic capillary hemangiomas are extremely rare and have been described only a handful of times in the literature. Chung et al. described a 47-year-old male with an incidental intradural capillary hemangioma at $\mathrm{T7}$ resulting in sensory impairment. ${ }^{6}$ Two additional cases have reported thoracic capillary hemangioma arising secondary to prior spinal trauma, ${ }^{7,8}$ with accompanying pain, sensory, and motor deficits. Furthermore, case reports most commonly describe patients at or above the age of 50 years. We were only able to find three cases involving patients under the age of 30 , both of which described intradural/extramedullary pathology and which were localized to the cervical ${ }^{9}$ or lumbar ${ }^{10,11}$ spine.

Among the previously published cases, all described a chronic to subacute process of symptomatic spinal compression attributed to mass effect and nerve root irritation from a growing capillary hemangioma. No case reports to date have described acute traumatic rupture with expanding hematoma causing neurological deficits. Indeed, traumatic and spontaneous ruptures of capillary hemangiomas in other anatomical locations have been described, including the liver, ${ }^{12,13}$ stomach, ${ }^{14}$ and kidney; ${ }^{15}$ however, this has yet to be reported in the spinal cord.

Complete resection with laminectomy is the preferred treatment of choice for compressive capillary hemangiomas and was performed in all reported cases. In this unique case of acute traumatic rupture, we were able to emergently decompress the spinal cord with removal of the vascular mass and evacuate the hematoma. 


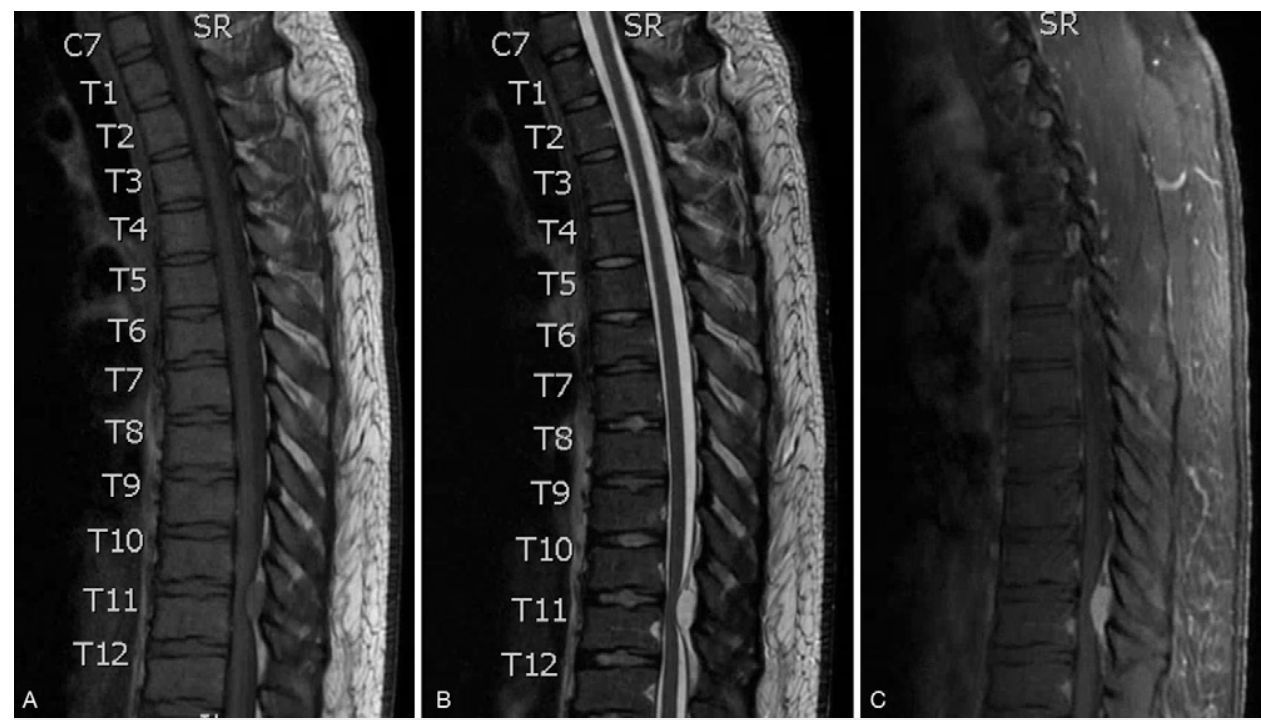

FIG. 4. MRI after 24 hours showing enlargement of the lesion to 7-8 $\mathrm{mm}$ and increased cord compression at T10-11 on (A) T1 sequence and ( $B$ and C) T2 sequence.

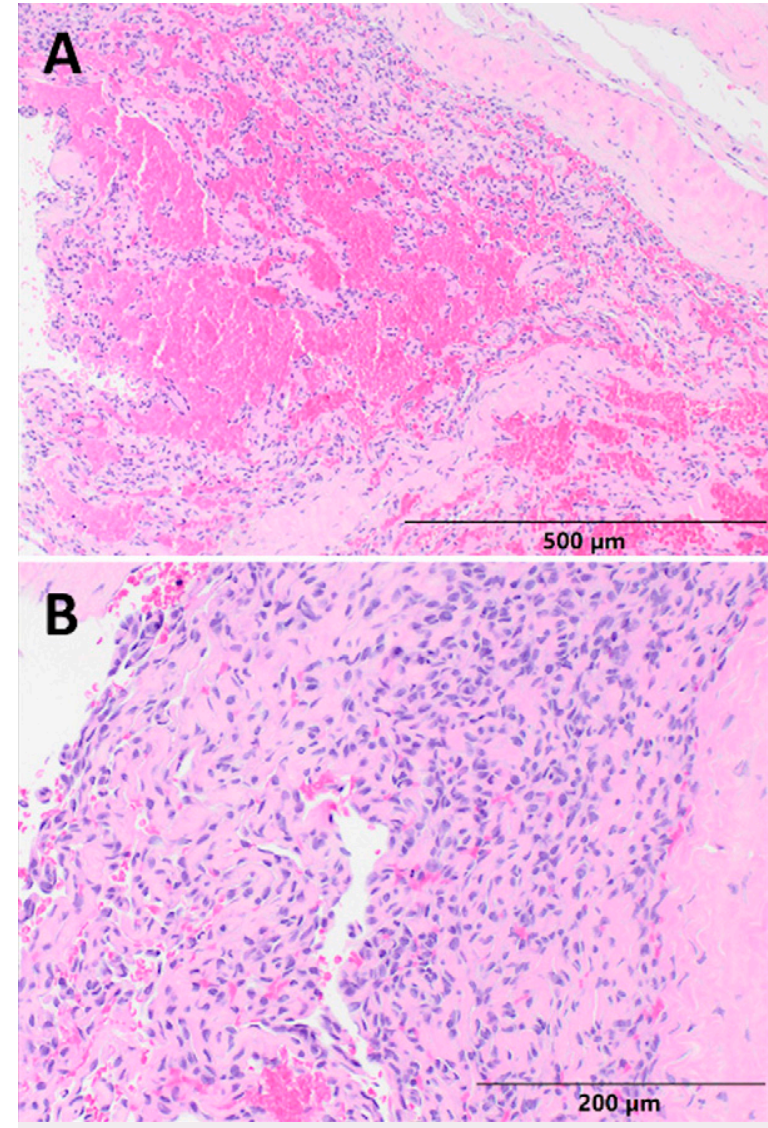

FIG. 5. A: A low-power image $(\times 100)$ shows a well-circumscribed proliferation of numerous thin-walled vessels with significant vascular congestion. B: A medium-power image $(\times 200)$ of a more cellular region that is composed of a compact proliferation of capillaries with slitlike vascular channels.

\section{Lessons}

Epidural thoracic capillary hemangiomas are exceedingly rare. To our knowledge, this is the first reported case of traumatic rupture of this pathology leading to acute neurological deficits. The patient's acute weakness and paresthesias were improved with urgent spinal decompression and hematoma evacuation, with the capillary hemangioma resected to avoid further injury. This case demonstrates that, although rare, capillary hemangioma rupture should be considered in the differential diagnosis for patients with acute spinal trauma and evolving deficits on examination in the absence of fracture or obvious spinal cord injury. Reimaging revealing an expanding hematoma may support this diagnosis, and the need for emergent decompression and evacuation should be guided by clinical presentation.

\section{References}

1. Abe M, Tabuchi K, Tanaka S, et al. Capillary hemangioma of the central nervous system. J Neurosurg. 2004;101(1):73-81.

2. Koeller KK, Rosenblum RS, Morrison AL. Neoplasms of the spinal cord and filum terminale: radiologic-pathologic correlation. Radiographics. 2000;20(6):1721-1749.

3. Nowak DA, Widenka DC. Spinal intradural capillary haemangioma: a review. Eur Spine J. 2001;10(6):464-472.

4. Xu H, Tong M, Liu J, Zhou G, Chen F. Purely spinal epidural capillary hemangiomas. J Craniofac Surg. 2018;29(3):769-771.

5. Shen G, Su M, Zhao J, Liu B, Kuang A. Capillary hemangioma of thoracic spinal cord: PET/CT and MR findings. Clin Nucl Med. 2017; 42(5):408-409.

6. Chung SK, Nam TK, Park SW, Hwang SN. Capillary hemangioma of the thoracic spinal cord. J Korean Neurosurg Soc. 2010;48(3):272-275.

7. Sudhir G, Jayabalan V, Manohar TH, Gadde S, Kumar V, Kailash K. Posttraumatic thoracic epidural capillary hemangioma - a rare case report. Surg Neurol Int. 2020;11:179.

8. Shilton H, Goldschlager T, Kelman A, Xenos C. Delayed post-traumatic capillary haemangioma of the spine. J Clin Neurosci. 2011; 18(11):1546-1547. 
9. Bouali S, Maatar N, Bouhoula A, Abderrahmen K, Kallel J, Jemel $\mathrm{H}$. Intradural extramedullary capillary hemangioma in the upper cervical spine: first report. World Neurosurg. 2016;92:587.e1-587.e7.

10. Miri SM, Habibi Z, Hashemi M, Meybodi AT, Tabatabai SA. Capillary hemangioma of cauda equina: a case report. Cases J. 2009; 2(1):80.

11. Choi BY, Chang KH, Choe G, et al. Spinal intradural extramedullary capillary hemangioma: MR imaging findings. AJNR Am J Neuroradiol. 2001;22(4):799-802.

12. Ribeiro MA Jr, Papaiordanou F, Gonçalves JM, Chaib E. Spontaneous rupture of hepatic hemangiomas: A review of the literature. World J Hepatol. 2010;2(12):428-433.

13. Beatty JS, Mitchell JW, Holsten SB, Ferdinand $\mathrm{CH}$. Traumatic rupture of a previously undiagnosed giant hepatic hemangioma. Am Surg. 2013;79(9):e314-e315.

14. Lin $\mathrm{CH}$, Hsieh HF, Yu JC, et al. Spontaneous rupture of a large exogastric hemangioma complicated by hemoperitoneum and sepsis. J Formos Med Assoc. 2006;105(12):1027-1030.

15. Poznańska G, Wlazlak M, Hogendorf P, Szymański D, Strzelczyk J, Durczyński A. Ruptured hemangioma of a native kidney: an unusual cause of postoperative hemorrhage in kidney transplant recipients. Ann Transplant. 2017;22:138-140.

\section{Disclosures}

The authors report no conflict of interest concerning the materials or methods used in this study or the findings specified in this paper.

\section{Author Contributions}

Conception and design: Stone, Kidwell, Ciacci. Acquisition of data: Stone, Kidwell, Ciacci. Analysis and interpretation of data: all authors. Drafting the article: Stone, Kidwell. Critically revising the article: Stone, Ciacci. Reviewed submitted version of manuscript: Stone, Kidwell, Goodwill. Approved the final version of the manuscript on behalf of all authors: Stone. Administrative/technical/material support: Ciacci. Study supervision: Ciacci.

\section{Correspondence}

Lauren E. Stone: University of California, San Diego, La Jolla, CA. wtaylor@ucsd.edu. 